\title{
Anatomical correction for complete transposition and double outlet right ventricle: intermediate assessment of functional results
}

\author{
C LINCOLN, A N REDINGTON, K LI, S MATTOS, E A SHINEBOURNE, \\ M L RIGBY \\ From the Brompton Hospital, London
}

SUMMARY Thirty three patients were followed up after anatomical correction of transposition of the great arteries or double outlet right ventricle and subpulmonary ventricular septal defect (Taussig-Bing anomaly). There were no late deaths and clinical progress was excellent. Cardiac catheterisation was performed in 17 patients two weeks to 44 months after operation. There were six patients with simple transposition, six with complete transposition and large ventricular septal defect, and five with the Taussig-Bing anomaly. Pressure gradients across the right ventricular outflow tract ranged from 5 to $72 \mathrm{~mm} \mathrm{Hg}$, being $>40 \mathrm{~mm} \mathrm{Hg}$ in five patients. No patient was shown to have important valvar regurgitation and in 15 patients the coronary anastomoses were widely patent. Left ventricular function was assessed from digitised ventriculograms. Ventricular volume, shape, and ejection fraction were all normal for the group although patients with complex transposition showed a significantly lower mean (SD) ejection fraction than those with simple transposition (62(9) vs $77(9)$ ). Analysis of regional wall motion showed a totally normal pattern in four patients; however, in seven patients a characteristic abnormality of anterior hypokinesis with delayed onset of inward wall motion was seen.

Anatomical correction of transposition of the great arteries and the Taussig-Bing anomaly can be performed with satisfactory anatomical and functional results. The implications of the left ventricular wall motion abnormalities is unknown.

Since the first report of successful anatomical correction of complete transposition by Jatene et al in $1975,{ }^{1}$ interest in repair at the arterial level has been rekindled. The technique of anatomical correction has been applied to patients with intact ventricular septum $^{23}$ and with ventricular septal defect ${ }^{4}$ as well as to patients with double outlet right ventricle and subpulmonary ventricular septal defect (TaussigBing anomaly. ${ }^{5}$ This report presents the intermediate assessment of cardiac function and growth of the heart and great vessels in 17 patients after this type of operation.

Requests for reprints to Mr C Lincoln, FRCS, Brompton Hospital, Fulham Road, London SW36HP.

Accepted for publication 12 May 1986

\section{Patients and methods}

\section{PATIENTS}

Between October 1981 and January 1986, 45 children underwent anatomical correction of complete transposition or double outlet right ventricle. Twenty one had complete transposition of the great arteries and a ventricular septal defect, 12 had an intact ventricular septum, and 12 had double outlet right ventricle and subpulmonary ventricular septal defect. Age at operation ranged from 18 hours to 6 years (mean 11.3 months) and weight ranged from 2.6 to $16.4 \mathrm{~kg}$ (mean $6.1 \mathrm{~kg}$ ). The group with complete transposition and an intact ventricular septum was younger (mean 1.2 months) and the mean weight was less $(3.5 \mathrm{~kg})$ than that of the other two groups. Associated congenital heart defects were present in twelive patients. These included aortic coarctation in five, more than one ventricular septal defect in three, 
right ventricular hypoplasia in two, left juxtaposition of the atrial appendage in two, and one patient each with interrupted aortic arch at the aortic isthmus, left ventricular outflow tract obstruction, or the Wolff-Parkinson-White syndrome.

Eleven patients had had banding of the pulmonary trunk. Four of these patients had also had repair of coarctation; four had had atrial septectomy or a Blalock-Hanlon procedure, and one had had construction of a systemic to pulmonary artery shunt. All patients with complete transposition and intact ventricular septum had an arterial ductus. One patient had had banding of the pulmonary trunk to "prepare" the left ventricle as described by Yacoub et $\mathrm{al}^{2}$ because of important right atrioventricular valve incompetence with poor right ventricular function.

We have reported our early experience and modification of the Jatene operation elsewhere. ${ }^{6}$

The thirty three surviving patients were followed from three to 60 months after operation (mean 15 months); there were no late deaths. After four months one patient with double outlet right ventricle required reoperation for closure of a large residual ventricular septal defect. After this was accomplished he was found to have suprasystemic right ventricular pressure secondary to severe subvalvar muscular outflow tract obstruction. This necessitated an extensive infundibular resection and patching of the outflow tract. Two patients who required plication of a paralysed hemidiaphragm (one was the patient reoperated for the residual ventricular septal defect) continued to have breathlessness at rest for three months. The remaining thirty one patients $(93 \%)$ have no symptoms and are thriving. No patient has clinical evidence of ventricular dysfunction, aortic or tricuspid insufficiency, myocardial ischaemia, or arrhythmias.

\section{CARDIAC CATHETERISATION}

Seventeen patients had right and left heart catheterisation with biplane angiography two weeks to 44 months after operation (table 1). Six had simple transposition, six had transposition and ventricular septal defect, and five had double outlet right ventricle. Age at repair in these patients ranged from 1 to 2190 days. The mean (SD) age at repair for those with simple transposition, transposition and ventricular septal defect, and double outlet right ventricle was 66(101), 672 (775), and 385 (399) days respectively. There was a significant difference in age at repair of simple transposition and transposition with ventricular septal defect $(p=0.03$, Mann Whitney).

Five of the 17 patients showed an appreciable pressure gradient ( $>40 \mathrm{~mm} \mathrm{Hg}$ ) across the right ventricular outflow tract. The measured gradients ranged from 5 to $72 \mathrm{~mm} \mathrm{Hg}$ (mean 50) with an average right ventricular systolic pressure of $68 \mathrm{~mm} \mathrm{Hg}$. The level of obstruction was infundibular in three,

Table 1 Individual clinical and haemodynamic data in patients after anatomical correction

\begin{tabular}{|c|c|c|c|c|c|c|c|c|c|}
\hline Case No & $\begin{array}{l}\text { Age at } \\
\text { catheterisation } \\
\text { (days) }\end{array}$ & $\begin{array}{l}B S A \\
\left(m^{2}\right)\end{array}$ & $\begin{array}{l}\text { Age at } \\
\text { operation } \\
\text { (days) }\end{array}$ & $\begin{array}{l}R V \\
\text { pressure } \\
(\mathrm{mm} \mathrm{Hg})\end{array}$ & $\begin{array}{l}P A \\
\text { pressure } \\
\text { (mm Hg) }\end{array}$ & $\begin{array}{l}R V \mid P A \\
\text { gradient } \\
\text { (mm } \mathbf{H g})\end{array}$ & $\begin{array}{l}L V \\
\text { pressure } \\
(\mathrm{mm} \mathrm{Hg})\end{array}$ & $\begin{array}{l}\text { Ao } \\
\text { pressure } \\
(\mathrm{mm} \mathrm{Hg})\end{array}$ & $\begin{array}{l}\text { LV } \mid \text { Ao } \\
\text { gradient } \\
(\boldsymbol{m m} \mathbf{H g})\end{array}$ \\
\hline \multicolumn{10}{|c|}{ Transposition and intact ventricular septum: } \\
\hline 1 & 60 & $0 \cdot 124$ & 5 & $64 / 1$ & $26 / 6-13$ & 38 & $100 / 1$ & $100 / 70$ & $\mathbf{0}$ \\
\hline 2 & 330 & 0.47 & 30 & $98 / 6$ & $26 / 11$ & 72 & $92 / 7$ & $92 / 56$ & 0 \\
\hline 3 & 660 & 0.48 & 255 & $69 / 0-4$ & $29 / 10$ & 40 & $160 / 0-5$ & $130 / 50$ & 20 \\
\hline 4 & 420 & 0.48 & 1 & $27 / 3$ & $17 / 8$ & 10 & $98 / 10$ & $90 / 50$ & 0 \\
\hline 5 & 600 & 0.63 & i & $45 / 7$ & $40 / 8-20$ & $5 \cdot 0$ & $76 / 10$ & $70 / 45$ & \\
\hline 6 & 1260 & 0.66 & 105 & $65 / 1$ & $21 / 15-10$ & 49 & $130 / 14$ & $108 / 68$ & 22 \\
\hline \multicolumn{10}{|c|}{ Transposition + VSD: } \\
\hline 7 & 480 & 0.35 & 450 & $30 / 0$ & $25 / 10-15$ & 5 & $80 / 10$ & $80 / 35$ & 0 \\
\hline 8 & 300 & 0.43 & 10 & $92 / 8$ & $20 / 14$ & 72 & $93 / 7$ & & \\
\hline 9 & 270 & 0.43 & 240 & $40 / 3$ & $26 / 10$ & 14 & $79 / 5$ & $76 / 50 / 60$ & 3 \\
\hline 10 & 760 & 0.5 & 540 & $62 / 0-7$ & $35 / 15$ & 30 & $118 / 0-8$ & $100 / 62$ & 18 \\
\hline 11 & 2520 & 0.79 & 2196 & $36 / 6$ & $20 / 4-5$ & 16 & $106 / 5$ & $106 / 66$ & 0 \\
\hline 12 & 962 & 0.46 & 600 & $95 / 6$ & $26 / 4$ & 72 & $92 / 7$ & $92 / 56$ & $\mathbf{0}$ \\
\hline \multicolumn{10}{|c|}{ Double outlet right ventricle: } \\
\hline 13 & 300 & $0 \cdot 22$ & 180 & $50 / 0$ & $25 / 9$ & 25 & $100 / 0$ & $110 / 70$ & 10 \\
\hline 14 & 84 & 0.23 & 60 & & & & $105 / 10$ & $135 / 65$ & \\
\hline 15 & 180 & 0.36 & 42 & $51 / 5$ & $22 / 10$ & 29 & $80 / 8$ & $77 / 50$ & 3 \\
\hline $\begin{array}{l}16 \\
17\end{array}$ & $\begin{array}{l}1020 \\
1488\end{array}$ & $\begin{array}{l}0.52 \\
0.6\end{array}$ & $\begin{array}{r}840 \\
1474\end{array}$ & $\begin{array}{l}40 / 0-5 \\
60 / 15\end{array}$ & $\begin{array}{l}25 / 10-18 \\
50 / 12\end{array}$ & $\begin{array}{l}25 \\
10\end{array}$ & $\begin{array}{l}90 / 0-6 \\
95 / 16\end{array}$ & $\begin{array}{r}90 / 50 \\
110 / 68\end{array}$ & $\begin{array}{l}\mathbf{0} \\
\mathbf{0}\end{array}$ \\
\hline
\end{tabular}

BSA, body surface area; RV, right ventricular; PA, pulmonary artery; LV, left ventricular; Ao, aortic; VSD, ventricular septal defect. 

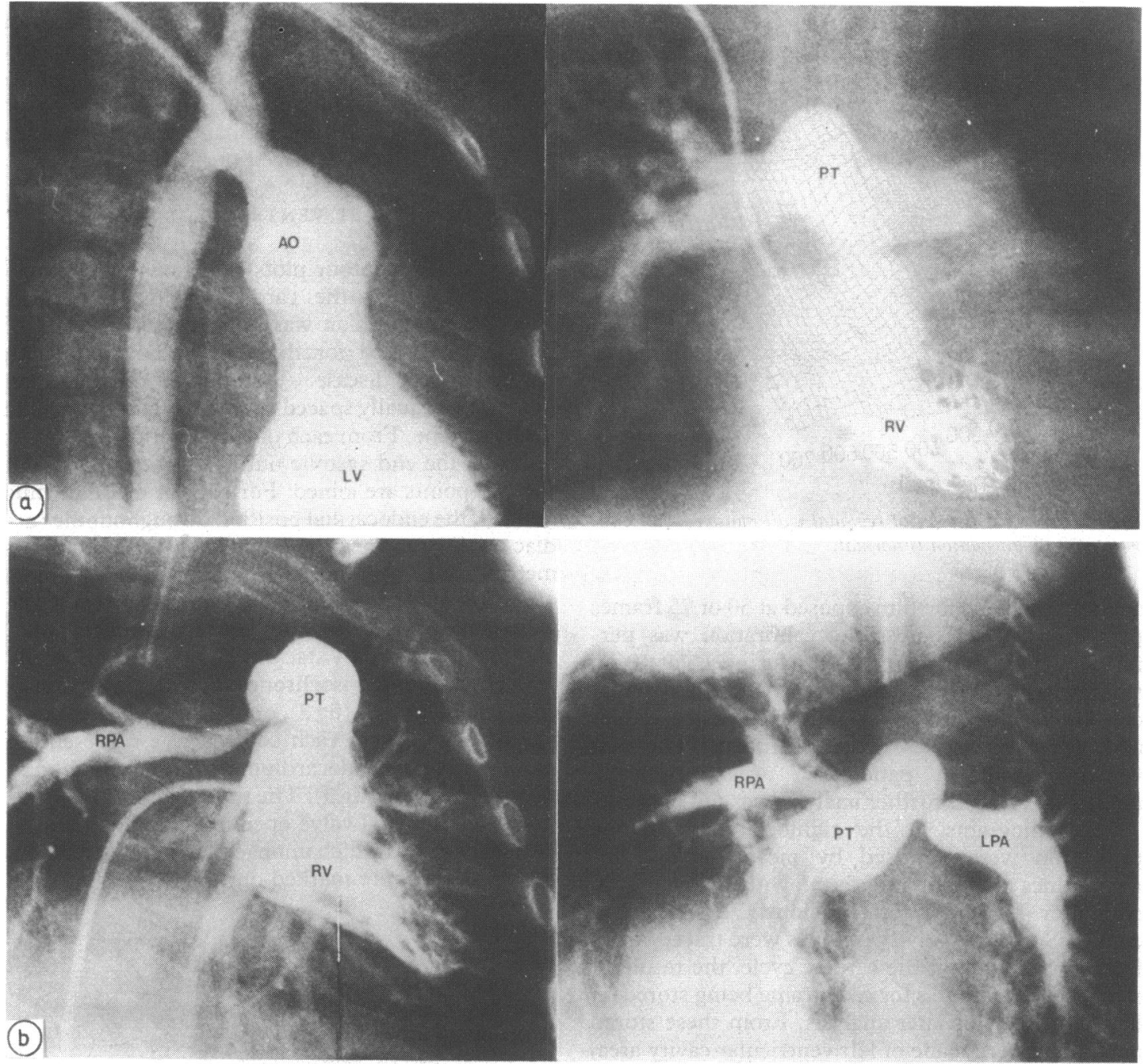

Fig 1 (a) Left and right ventriculograms showing normal postoperative appearances a year after operation. The great vessel anastomoses are widely patent. (b) Pulmonary angiogram of a patient repaired by the Lecompte manoeuvre. There is attenuation of the origin of right and left pulmonary arteries as they straddle the aorta (RV-distal PA gradient $=72 \mathrm{~mm} \mathrm{Hg}$ ).

supravalvar in one, and beyond the pulmonary artery bifurcation due to attenuation of the right and left pulmonary arteries in another (fig 1 ). A residual ventricular septal defect was identified in three patients but only one required reoperation, the other two defects being unimportant (pulmonary blood flow:systemic blood flow $<1.5)$. One patient with simple transposition had a $22 \mathrm{~mm} \mathrm{Hg}$ pressure drop across the left ventricular outflow tract. The coronary artery anastomoses were shown to be widely patent in all but two patients. These two, in whom the left coronary artery was not well visualised, have subsequently undergone 24 hour electrocardiographic monitoring which did not show evidence of myocardial ischaemia. No patient had important valvar regurgitation demonstrated by angiography. There were no significant differences among the three groups for age at study, body surface area at the time of study, and interval between repair and study.

ANALYSIS OF LEFT VENTRICULAR ANGIOGRAMS Left ventriculograms were performed retrogradely 


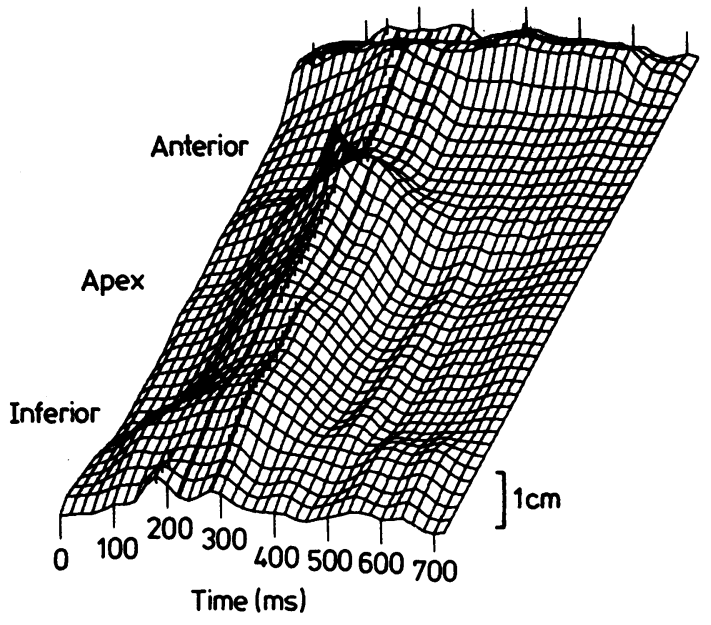

Fig 2 Isometric display of regional wall motion from patient 2. Wall motion is normal.

and recorded on cine film exposed at 50 or 75 frames per second. When possible, calibration was performed by obtaining a recording during a 5 or $10 \mathrm{~cm}$ shift of the patient with the catheter in the left ventricle. Only sinus beats were analysed; extrasystoles and postextrasystoles were excluded. The left ventriculogram in patient 17 was technically unsatisfactory and further analysis was not possible.

Cineangiograms in the right anterior oblique projection were digitised by means of a Summagraphics digitiser interfaced with a Prime $\mathbf{7 5 0}$ computer by a method previously described in detail. ${ }^{7}$ Successive cavity outlines were traced frame by frame thoughout the cardiac cycle, the resultant strings of coordinates for each frame being stored on magnetic tape for later analysis. From these stored data, plots were made of left ventricular cavity area, derived cavity volume (area-length method), rate of change of volume, and shape index change throughout the cardiac cycle.

Ventricular volumes were later standardised by dividing by body surface area and expressed as $\mathrm{ml} / \mathrm{m}^{2}$. Ejection fraction was calculated as stroke volume divided by end diastolic volume. Peak rate of ventricular filling (PFR) was derived as the corresponding maximum rate of change of ventricular volume and was standardised by dividing by end diastolic volume (PFR/EDV $\stackrel{=}{=} \mathrm{dVol} / \mathrm{dT}$ per unit EDV). When calibration of the angiograms was not possible, ejection fraction and normalised peak rate of ventricular filling were calculated from an assumed end diastolic volume of $100 \mathrm{ml}$. No attempt at absolute volume measurement was made under these circumstances. Shape index, derived as $4 \pi$ cavity area/perimeter ${ }^{2}$, is a measure of the roundness of the left ventricular cavity. ${ }^{8}$ It is independent of cavity size and has a value of 1 when the cavity outline is circular and 0 when complete cavity obliteration occurs. Measurements of end diastolic shape index and systolic change in shape index were made and compared with reported normal values. ${ }^{9}$

\section{ANALYSIS OF LEFT VENTRICULAR WALL MOVEMEN T}

Isometric and contour plots of regional wall movement throughout the cardiac cycle were made. Regional wall motion was studied by a method of display developed for the study of patients with coronary artery disease. ${ }^{7}$ This method depends upon defining 40 equally spaced points on the end diastolic cavity outline. From each of these points the nearest point on the end systolic outline is determined and the two points are joined. For each of the lines thus defined, the endocardial position throughout the cardiac cycle was measured and expressed in millimetres from its end diastolic position. Thus 40 plots of endocardial motion throughout the cardiac cycle were generated. A three dimensional isometric display was produced by stacking the 40 plots obliquely with superimposed isochrones representing the successive cine frames (fig 2 ), or alternatively a contour map was produced, each contour line representing movement of the endocardium by $1 \mathrm{~mm}$ from the end diastolic position (fig 3 ). The times of minimum cavity area and mitral valve opening (corresponding to the cine frame in which unopacified blood first enters the ventricle) were marked on both displays.

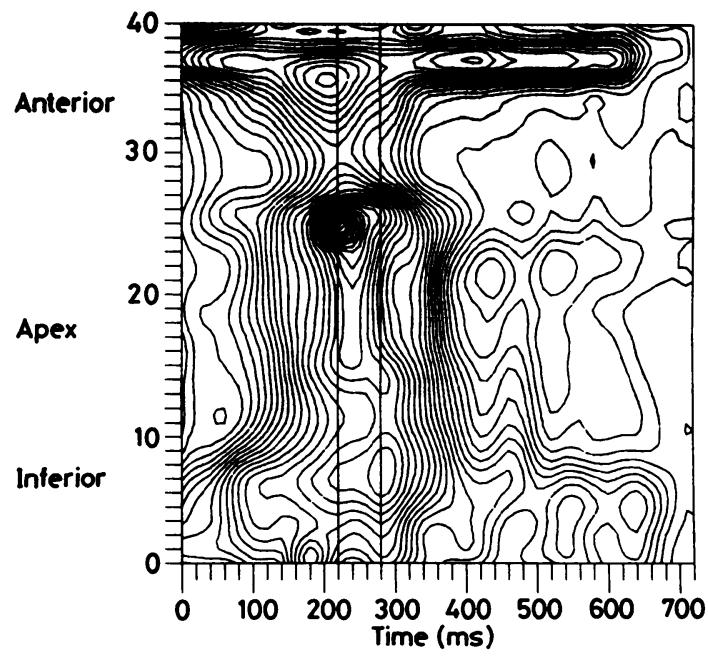

Fig 3 Contour display of the same patient as in Fig 1. The vertical lines mark the time of minimum cavity area and mitral valve opening. See text for full description. 
Anatomical correction for complete transposition and double outlet right ventricle

le 2 Individual clinical and angiographically derived data in patients after anatomical correction

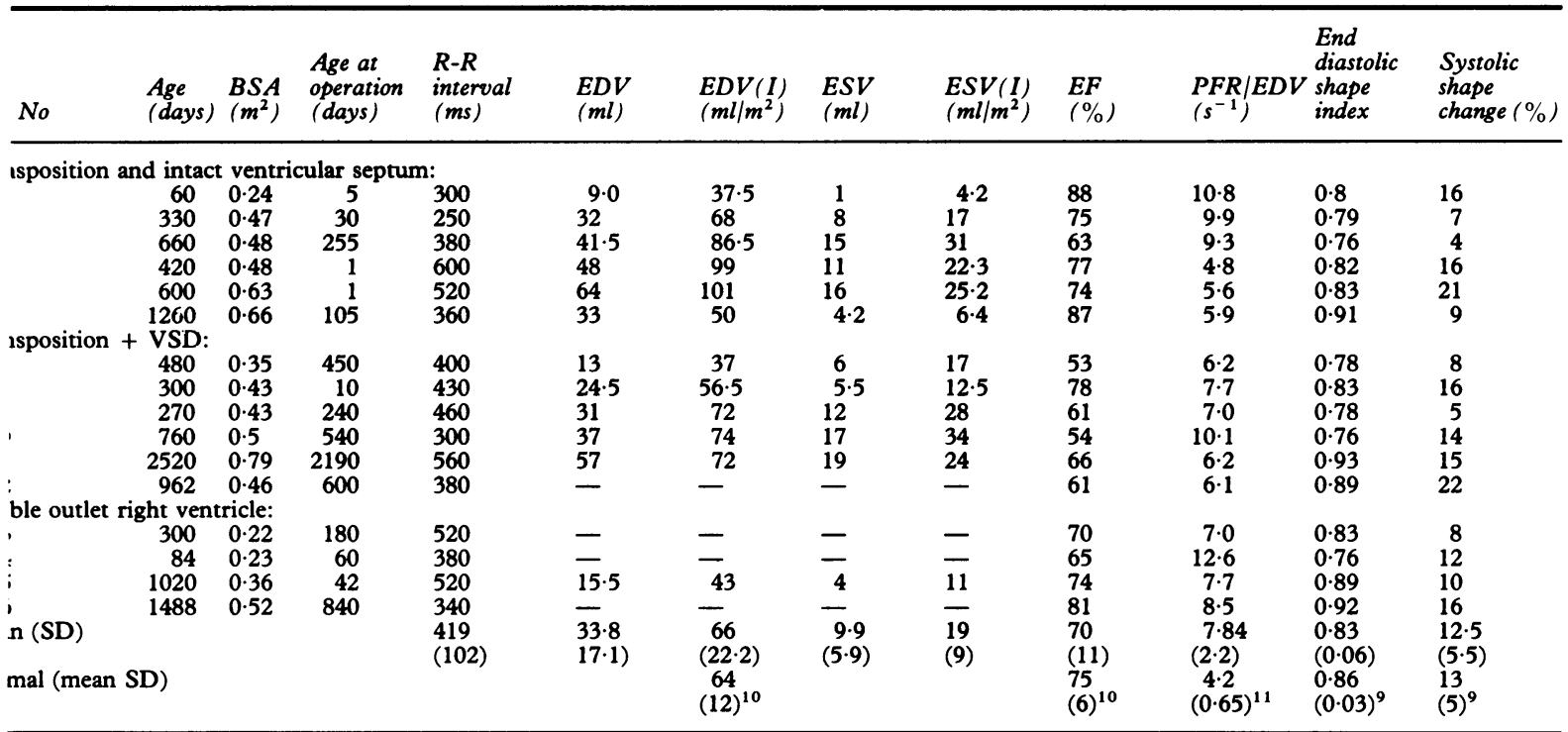

I, body surface area; $\operatorname{EDV}(\mathrm{I})$, end diastolic volume (index); ESV(I), end systolic volume (index); EF, ejection fraction; PFR, peak filling rate.

STATISTICAL METHODS

Results were analysed by standard t tests; a $p$ value of $<0.05$ was considered to be significant. Linear regression by means of the least squares method was used to examine possible correlations between variables.

\section{Results}

GLOBAL LEFT VENTRICULAR FUNCTION

Table 2 shows that when all patients are analysed together, mean (SD) end diastolic volume index and end systolic volume index were $66(22 \cdot 2)$ and $19(9.6) \mathrm{ml} / \mathrm{m}^{2}$ respectively. These figures were not significantly different from previously reported normal values. ${ }^{10}$ Similarly, ejection fraction was well maintained at $70(11) \%$. When the groups were analysed separately, however, patients with simple transposition had a significantly higher left ventricular ejection fraction (77 (9)\%) than did patients with transposition and ventricular septal defect $(62(9) \%$, $p<0.02)$. There was no difference between ejection fraction for the double outlet right ventricle group and that for both transposition groups. Although there was a tendency for left ventricular ejection fraction to fall as age at operation increased, this inverse relation did not reach statistical significance ( $r=-0.29$ for all patients, $r=-0.39$ for patients with transposition only). Peak left ventricular filling rate divided by end diastolic volume (PFR/EDV) was $7 \cdot 84(2 \cdot 2) \mathrm{s}^{-1}$, significantly higher than normal $(\mathrm{p}=0.001)^{11}$ Mean $\mathrm{R}-\mathrm{R}$ interval was only 419 (102) $\mathrm{ms}$, however, and there was a significant negative correlation between PFR/EDV and $R-R$ interval ( $r=0.66, \mathrm{p}<0.01)$.

End diastolic shape index for the entire group was $0.83(0.06)$. The systolic change in shape index was $12.5(5 \cdot 5) \%$. These figures resemble reported normal values ${ }^{9}$ and were not related to ventricular volumes of ejection fraction.

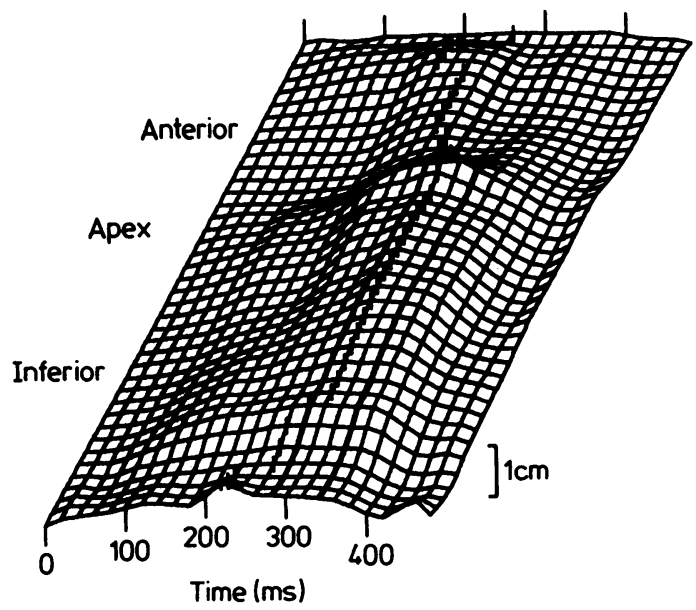

Fig 4 Isometric display of regional wall motion in patient 7. There is a localised area of hypokinesia along the anterior wall. 


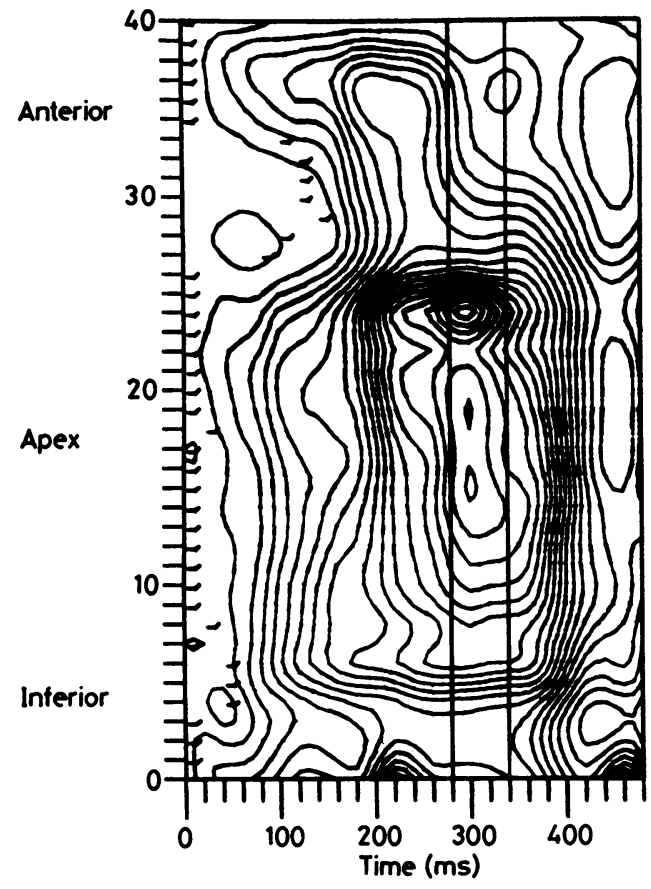

Fig 5 Contour display from same patient as in Fig 4. There is delay in onset of inward movement marked by the short horizontal lines and hypokinesia in segments 30-35.

REGIONAL LEFT VENTRICULAR FUNCTION

Figures 2 and 3 show normal patterns of wall motion. Onset of inward wall motion is synchronous, with less than $75 \mathrm{~ms}$ between onset in the earliest and latest segments to move. Peak inward motion occurs within $60 \mathrm{~ms}$ in all regions of the ventricle and is of uniform amplitude. There is little appreciable movement during isovolumic relaxation (the interval between minimum cavity area and mitral valve opening) which is followed by synchronous relaxation. This pattern of wall motion was seen in only four patients. In seven of the patients a characteristic abnormality was seen, mild anterior hypokinesia, which usually affected the apical segment of the free wall. This was associated with a delay in the onset of inward wall motion of the affected region, and in three of these patients there was, in addition, a delay in peak inferior inward wall motion of more than $60 \mathrm{~ms}$ (figs 4 and 5). In a further two patients there was isolated inferior wall hypokinesia (figs 6 and 7), and segmental early relaxation of the anterior wall with $>4 \mathrm{~mm}$ of outward wall occurring during isovolumic relaxation was seen in another. Inconsistent abnormalities of timing or amplitude of wall motion were seen in the remainder. Wall motion abnormal-

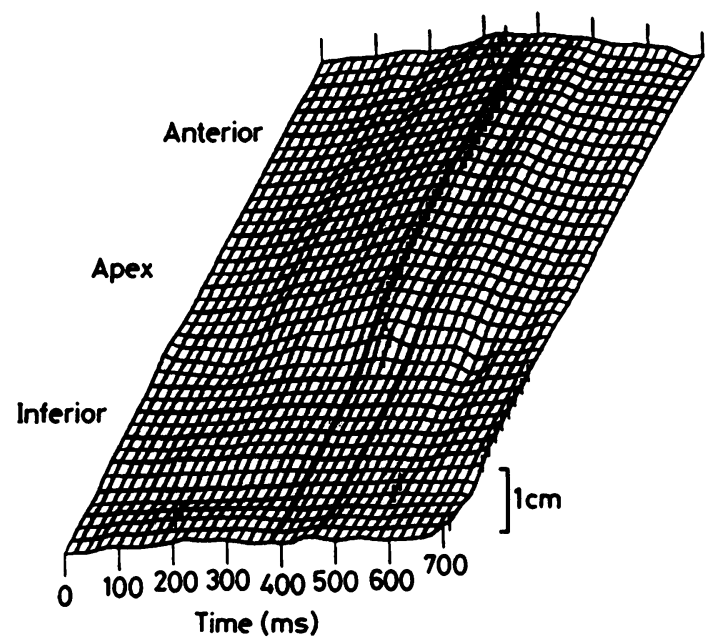

Fig 6 Isometric display of regional wall motion in patient 8. There is inferior hypokinesia.

ities seemed to be equally common in all groups and were independent of other indices of ventricular function.

\section{Discussion}

The theoretical advantages of using the left ventricle as the systemic pumping chamber have become even

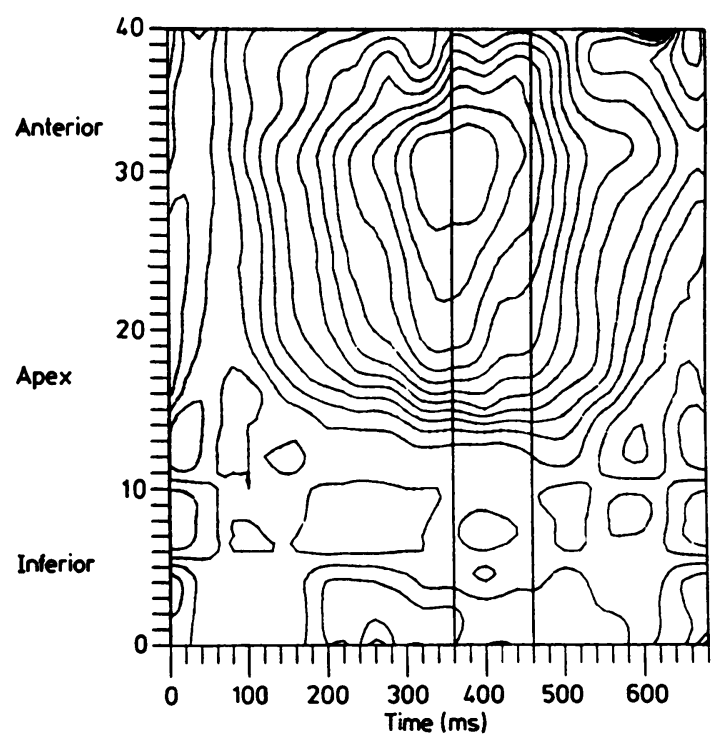

Fig 7 Contour display from same patient as in Fig 6 showing hypokinesia in segments 0-12 corresponding to the inferior wall of the ventricle. 
more attractive after several studies that have cast doubt on the long term ability of the morphologically right ventricle to perform in this role after atrial redirection procedures. ${ }^{12-14}$ Functional data after anatomical correction are limited, however, and postoperative follow up is necessarily short. None the less, several investigators examining several variables have shown that left ventricular function is normal or near normal after this procedure. 91015 Furthermore, it has been suggested that the functional results of the operation may be improved by a reduction in the age at which it is performed. ${ }^{916} \mathrm{Our}$ results generally accord with these conclusions. Ejection fraction and shape index-changes in our patients resembled those previously reported when an identical method of analysis was used. ${ }^{9}$ The observation that ejection fraction was lower in patients with transposition and ventricular septal defect than in those with simple transposition was unexpected, however, and contradicts the findings of Arensman et al who showed reduced ejection fraction in their patients with simple transposition. ${ }^{9}$ Small differences in operative technique are unlikely to be sufficient to explain this finding but the significant higher age at operation in patients with ventricular septal defect perhaps offers a more likely explanation and supports the hypothesis that earlier operation may preserve left ventricular function. Interestingly, in the small number of patients with double outlet right ventricle the opposite may be true, there being a tendency for ejection fraction to improve as their age at operation increased $(r=0.65$, $\mathrm{p}=\mathrm{NS}$ ).

Left ventricular filling characteristics have not been studied in detail in patients of this age. In our patients peak ventricular filling rates scaled for end diastolic volume (PFR/EDV) were higher than those seen in normal adults. ${ }^{11}$ There was a significant relation, however, between normalised peak filling rate and heart rate, and indeed, the increased rate of ventricular filling that we have observed may be explained by the relatively high heart rate in our patients at the time of study.

Despite normal measurements of global left ventricular function, frame by frame analysis of left ventricular wall motion showed a totally normal pattern in only four patients. Regional abnormalities of timing or amplitude of wall motion were demonstrated in the remainder. In seven of the patients a characteristic pattern of delayed onset of inward motion and hypokinesis of the anterior wall was seen. The implications of these and other abnormalities are not clear. No preoperative data are available and it is possible that such changes may be the result of preoperative arterial desaturation. Other possibilities include perioperative interference with coronary flow, or they may represent the minor disturbances in ventricular wall motion previously recorded with $M$ mode echocardiography after all types of open heart operation. Whatever their cause, it should be noted that these abnormalities were detected only when complex methods of analysis of regional wall motion were used, and these abnormalities appeared to be independent of preoperative anatomy and other indices of ventricular functon. The long term implications of these abnormalities are equally unclear. There is some evidence from a recent echocardiographic study that abnormal septal motion detected in the early postoperative period in these patients tends to resolve with time ${ }^{17}$ and follow up studies will be required to assess the progression of the more subtle abnormalities that we have described.

Several of the potential problems that were expected with anatomical correction ${ }^{18}$ were not observed in our series of patients. Functional results as judged by symptoms and by left ventricular function measured angiographically have been excellent. With the exception of one patient with a single coronary artery ostium operated upon early in our experience, coronary artery transfer has been feasible in all patients showing a wide variation of coronary artery anatomy. As predicted by animal studies, ${ }^{19}$ good growth of the coronary anatomoses was demonstrated both by the postoperative angiograms and by the lack of signs of myocardial ischaemia in the survivors.

In conclusion, we have shown that satisfactory anatomical and functional results can be obtained after the anatomical correction procedure for simple and complex transposition of the great arteries and the Taussig-Bing anomaly. Further studies are required to assess the importance of the left ventricular wall motion abnormalities that are often found in these patients.

We thank Dr D Gibson for his helpful criticisms of the manuscript.

\section{References}

1 Jatene AD, Fontes VF, Paulista PP, et al. Successful anatomic correction of transposition of the great arteries. A preliminary report. Arq Bras Cardiol 1975;28:464-7.

2 Yacoub MH, Radley-Smith R, McLaurin R. Twostage operation for anatomical correction of transposition of the great arteries with intact interventricular septum. Lancet 1977;i:1275-8.

3 Lincoln C, Lima R, Rigby ML. Anatomical correction of simple transposition of the great arteries during 
neonatal transition. Lancet 1983;ii:39.

4 Bical O, Hazan E, Lecompte Y, et al. Anatomic correction of transposition of the great arteries associated with ventricular septal defect: midterm results in $\mathbf{5 0}$ patients. Circulation 1984;70:891-7.

5 Yacoub MH, Radley-Smith R. Anatomic correction of the Taussig-Bing anomaly. $\mathcal{F}$ Thorac Cardiovasc Surg 1984;88:380-8.

6 Kanter K, Anderson RH, Lincoln C, Rigby ML, Shinebourne EA. Anatomic correction for complete transposition and double-outlet right ventricle. f Thorac Cardiovasc Surg 1985;90:690-9.

7 Gibson DG, Prewitt TA, Brown DJ. Analysis of left ventricular wall movement during isovolumic relaxation and its relation to coronary artery disease. Br Heart f 1976;38:1010-9.

8 Gibson DG, Brown DJ. Continuous assessment of left ventricular shape in man. Br Heart f 1975;37:904-10.

9 Arensman FW, Radley-Smith R, Yacoub MH, et al. Catheter evaluation of left ventricular shape and function one or more years after anatomic correction of transposition of the great arteries. Am $\mathcal{F}$ Cardiol 1983;52:1079-83.

10 Sievers $\mathrm{HH}$, Lange PE, Onnasch DGW, et al. Influence of the two stage anatomic correction of simple transposition of the great arteries on left ventricular function. Am $\mathcal{F}$ Cardiol 1985;56:514-9.

11 Hui WKK, Lee PK, Chow JSF, Gibson DG. Analysis of regional left ventricular wall motion during diastole in mitral stenosis. Br Heart $\mathcal{F}$ 1983;50:231-9.

12 Jarmakani MMJ, Canent RV. Preoperative and postoperative right ventricular function in children with transposition of the great vessels. Circulation 1974;50(suppl II):39-45.

13 Graham TP, Atwood GF, Boucek RJ, Boerth RC, Bender HW. Abnormalities of right ventricular function following Mustard's operation for transposition of the great arteries. Circulation 1975;52:678-84.

14 Ramsay JM, Venables AW, Kelly MJ, Kalff V. Right and left ventricular function at rest and with exercise after the Mustard operation for transposition of the great arteries. Br Heart $\mathcal{f}$ 1984;51:364-70.

15 Borow KM, Arensman FW, Webb C, Radley-Smith R, Yacoub M. Assessment of left ventricular contractile state after anatomic correction of transposition of the great arteries. Circulation 1984;69(i):106-12.

16 Okuda H, Nakazawa M, Imai Y, et al. Comparison of ventricular function after Senning and Jatene procedures for complete transposition of the great arteries. Am $\mathcal{f}$ Cardiol 1985;55:530-4.

17 Arensman FW, Radley-Smith R, Grieve L, Gibson DG, Yacoub MH. Computer assisted echocardiographic assessment of left ventricular function before and after anatomical correction of transposition of the great arteries. $\mathrm{Br}$ Heart $\mathcal{f}$ 1986;55:162-7.

18 Yacoub $\mathrm{MH}$. The case for anatomical correction of transposition of the great arteries. $\mathcal{F}$ Thorac Cardiovasc Surg 1979;78:3-6.

19 Brutel de la Reviere A, Quargebeur JM, Hennis PJ, Brutel de la Reviere G, Huysman HA, Brom AG. Growth of an aorto-coronary anastomosis. An experimental study in pigs. $\mathcal{F}$ Thorac Cardiovasc Surg 1983;86:383-99. 